Nevşehir Bilim ve Teknoloji Dergisi TARGíd Özel Sayı 208-213 2016

DOI: 10.17100/nevbiltek.210993

URL: http://dx.doi.org/10.17100/nevbiltek.210993

\title{
Kış Dinlenmesi Döneminde Uygulanan Düşük Sıcaklıkların Bazı Üzüm Çeşitlerinin Gelişimi Üzerine Etkileri
}

\author{
Ali Sabır ${ }^{1, *}$, Kevser Yazar $^{2}$, Zeki Kara ${ }^{1}$ \\ ${ }^{1}$ Selçuk Üniversitesi, Ziraat Fakültesi, Bahçe Bitkileri Bölümü, Konya \\ ${ }^{2}$ Selçuk Üniversitesi, Fen Bilimleri Enst., Bahçe Bitkileri Ana Bilim Dall, Konya
}

$\ddot{O ̈ z}$

Asmalarda kış dinlenmesi döneminde gerçekleşen düşük sıcaklıkların vejetatif gelişme ve kış gözü verimliliğini olumlu etkilediği bilinmektedir. Ancak, asmalarda soğuklama gereksiniminin süresi üzerine araştırmaların oldukça sınırlı olduğu ve çeşide özgü bilginin yetersiz olduğu görülmektedir. Özellikle örtü altı bağcıllğının önemli olduğu ülkemiz gibi bağcllık alanlarında erkenci üzüm çeşitlerinde soğuklama sürelerinin bilinmesi, mümkün olduğunca erken dönemde yüksek verim ve kaliteye ulaşılabilmesi için büyük önem taşımaktadır.

Kendi kökü üzerinde, yaklaşık $20 \pm 1$ litre katı hacimli saksılarda, standart bakım şartlarında yetiştirilen 2 yaşındaki Perle de Csaba, Superior Seedless ve Pembe Çekirdeksiz erkenci üzüm çeşitlerine ait asmalar eşit gelişme kuvvetinde 9'ar asmadan oluşan ikişer gruba ayrılmıştır. Birinci grup asmalar, yaz sonunda seradan dış koşullara çıkartılmış ve günlük gerçekleşen meteorolojik veriler takip edilerek $7{ }^{\circ} \mathrm{C}$ altında yaklaşı $300 \pm 15$ saat düşük sıcaklıkta tutulmuş ve bu sürenin sonunda sera içerisine alınmıştır. Diğer grup (kontrol) ise günlük ortalama sıcaklığ $11 \pm 3{ }^{\circ} \mathrm{C}$ olan 1 sıtmalı ve yarı kontrollü cam sera koşullarında tutulmuştur.

Düşük sıcaklık uygulamaları Perle de Csaba çeşidinde yaprak sayısı, ortalama sürgün uzunluğu, asma başına salkım sayısı ve salkımlı asma oranını arttırmıştır. Düşük sıcaklık, Superior Seedless çeşidinde sürgün çapı, sürgün uzunluğu, yaprak alanı, budama yaş ve kuru ağırlıklarını; Pembe Çekirdeksiz'de ise kış gözlerinde sürme oranı, yaprak sayısı, sürgün çapı, ortalama sürgün uzunluğu, yaprak alanı, budama yaş ve kuru ağırlıkları özelliklerini olumlu etkilemiştir. Sonuçlar genel olarak değerlendirildiğinde kış soğuklamasının asmaların vejetatif gelişimi ve verimlilik seviyelerini önemli derecede etkilediği düşünülmektedir.

Anahtar Kelimeler: Bağcılık, kış dinlenmesi, soğuklama ihtiyacı

\section{Effects of Cold Treatment in Winter Dormancy Period on Growth of Some Grapevine Cultivars}

\begin{abstract}
Low temperatures in dormancy period are known to have beneficial effects on the vegetative development and bud fruitfulness of grapevines. But, the number of studies on duration of chilling exposure and specific response of cultivars are limited. Especially, precious knowledge on chilling requirement duration for early grape cultivars has great significance for greenhouse production in countries like Turkey. In this study, two years old vines of Perle de Csaba, Superior Seedless and Pembe Çekirdeksiz grape cultivars have sorted into two groups and cultivated in $20 \pm 1 \mathrm{~L}$ pots under standard cultivation practices in glasshouse. First group was taken outside the glasshouse for chilling treatment under $7^{\circ} \mathrm{C}$ for about $300 \pm 15 \mathrm{~h}$ and was moved into the glasshouse when the exposure time was completed. The other group (control) was continuously kept in semi-controlled glasshouse equipped with automatic heating system that maintained its inside mean temperature around $11 \pm 3^{\circ} \mathrm{C}$.

For Perle de Csaba cultivar, low temperature treatment significantly increased the leaf number, mean shoot length, cluster number per vine and the percentage of the vines bearing cluster. The treatment improved the shoot diameter, mean shoot length, leaf area, fresh and dry weight of pruning residue in Superior Seedless and bud break percentage, leaf number, shoot diameter, mean shoot length, leaf area, fresh and dry weight of pruning residue in Pembe Çekirdeksiz. Overall findings imply that winter chilling may improve the vegetative and reproductive developments of grapevines.
\end{abstract}

Keywords: Viticulture, winter dormancy, chilling requirement

* e-mail: asabir@selcuk.edu.tr 


\section{Giriș}

Asmaların kış döneminde belirli bir süre soğuk havaya maruz kalması, ilkbaharda tomurcukların bir örnek uyanması, sağlıklı bir şekilde çiçeklenmesi ve tane bağlaması için olumlu etkiye sahiptir. Soğuklama ihtiyacı olarak ifade edilen bu durum, ilk olarak 1950'de Weinberger tarafindan bazı meyveler için önerilmiştir. Weinberger, meyvelerde tomurcukların ilkbaharda çiçeklenebilmesi için kış mevsiminde 0 ve $7^{\circ} \mathrm{C}$ arasında geçirmesi gereken süreyi 'soğuklama gereksinimi' olarak tanımlamıştır [1].

Asmalarda soğuklamanın gerekliliği konusunda araştırıcılar arasında bazı farklılıklar bulunmakla birlikte, genellikle asmalarda 150-400 saat arasında soğuklamanın olumlu etkide bulunduğu belirtilmektedir [2, 3]. Ankara'da yapılan bir çalışmada, asma tomurcuklarının sağlıklı bir şekilde sürebilmesi için çeşitlere göre Çavuş’ta 100-150, Kalecik Karası'nda 100-200, Hamburg Misketi'nde 180-250 ve Hafızali'de 350-400 saatlik soğuklama süresine ihtiyaç olduğu saptanmıştır [4]. Dünyadaki çoğu bağclık ülkesinde bu süre pratikte karşılanmaktadır. Ancak Akdeniz İklimi'nin hüküm sürdüğü bazı yerlerde ve özellikle örtü altı bağcılığın yapıldığı üretim tekniklerinde soğuklama ihtiyacının dikkate alınmadığı ve bu duruma bağlı olarak verimde önemli kayıpların olduğu bilinmektedir. Botelho ve ark. [2], bağlarda 1lıman iklim koşullarında tomurcuk dormansisini erken kırmak için kimyasal uygulama gerekliliğini belirtmişlerdir. Tek tomurcuklu kesimlere \% 1.5 ve 3.0 sarımsak ekstraktı ve $\% 1.5$ hidrojen siyanamid püskürtmüşlerdir. Kontrol uygulamasına ise saf su uygulamışlardır. 3 parselde spreylemeden önce $0,168,336$ ve 508 saat soğuklamaya tutulmuştur. Bütün uygulamalar filizlenerek kontrol uygulamasına göre daha iyi geliştiğini gözlemlemişlerdir. Soğuklanmasını almamış çeliklerde bile 35 günde en etkili uygulama olan $\% 1.5$ hidrojen siyanamid uygulamasıyla $\% 80$ oranında filizlenmeye ulaşmışlardır. Uygulamadan 35 gün sonra 168 , 336 ve 508 saat soğuklanmış kesimlerde sarımsak ekstraktı uygulaması tomurcuk açmasını \% 70 artırmıştır. Cabernet Sauvignon çeşidi için soğuklama gereksinimi 336 saate yakın olduğunu belirtmişlerdir.

Literatür araştırmalarına göre, asmalarda kış soğuklama gereksiniminin süresi üzerine araştırmaların oldukça sınırlı olduğu görülmektedir. Ancak bazı araştırmacılar kış soğuklama gereksinimi üzerine araştırmalarda asmaların dengeli bir gelişme için kış döneminde soğuklama ihtiyacının karşılanması gerektiğini savunmaktadır. Bu çalışmada soğuk uygulamanın erken dönemde olgunlaşan ve örtü altı bağcılığına uygun özellikte olan standart üzüm çeşitlerinden Perle de Csaba, Superior Seedless ve Pembe Çekirdeksiz üzüm çeşitlerinin gelişimi üzerine etkileri araştırılmıştır.

\section{Materyal ve Metot}

Selçuk Üniversitesi Ziraat Fakültesi Bahçe Bitkileri Bölümüne ait araştırma seralarında yürütülen bu çalışmada erken dönemde olgunlaşan Perle de Csaba, Superior Seedless ve Pembe Çekirdeksiz üzüm çeşitleri kullanılmıştır. Çalışma, 3 tekerrürlü ve her tekerrürde 3 bitki olacak şekilde yaklaşık $20 \mathrm{~L}$ toprak kapasitesi olan saksılarda yürütülmüştür. Saksılarda yetiştirme ortamı olarak eşit miktarlarda torf $\left(1.034 \% \mathrm{~N}, 0.94 \% \quad \mathrm{P}_{2} \mathrm{O}_{5}, 0.64 \% \quad \mathrm{~K}_{2} \mathrm{O}, \mathrm{pH}: 5.88\right.$, Klassman $\left.{ }^{\circledR}\right)$ ve perlit karışımı kullanılmıştır. Araştırma başlangıcında 2 yaşında, kendi kökü üzerinde ve her saksıda bireysel olarak yetiştirilmekte olan asmalardan benzer gelişme kuvvetinde olanlar seçilmiştir. 
Uygulamada meteorolojik veriler dikkate alınarak bitkinin dinlenmeye girdiği sonbaharda, soğuklama grubu bitkiler dışarı alınmıştır. Diğer grup sera içerisinden çıkarılmamıştır. Soğuklama grubu meteorolojik veriler takip edilerek $+7.2^{\circ} \mathrm{C}$ altında yaklaşık $300 \pm \% 5$ saat süreyle soğuklamaya tabi tutulmuştur. Bitkilerin bulunduğu çevre sıcaklığı anlık olarak kaydedilerek takip edilmiş ve sıcaklığın 2.0 ile $+6.5^{\circ} \mathrm{C}$ aralığında olduğu belirlenmiştir (Datalogger Ebro EBI 20). Diğer grup (kontrol) ise günlük ortalama sıcaklığı $11 \pm 3{ }^{\circ} \mathrm{C}$ olan ısıtmalı ve yarı kontrollü cam sera koşullarında tutulmuştur. Soğuklama süresinin sonunda asmalar ısıtmalı cam sera içerisine alınmıştır. İç ortam hava hareketinin sağlanması için yan pencerelerden, ortam sıcaklığının düşürülmesi için de çatı havalandırma sistemlerinden yararlanılmıştır. Her iki grup asmalarında iç ortamda bulunduğu araştırma süresince sera içi günlük ortalama sıcaklığı gece $18 \pm 4$ ve gündüz $29 \pm 5^{\circ} \mathrm{C}$ olarak belirlenmiştir.

Sulama, gübreleme, kış ve yaz budaması, hastalık ve zararlılarla mücadele gibi işlemler bütün bitkilere standart olarak uygulanmıştır. Sulamalar hava koşullarına bağlı olarak 2-4 gün aralıklarla $3.0 \pm$ 0.5 litre / asma olacak şekilde elle gerçekleştirilmiştir. Yaz dönemi başlangıcında asmalara N, P, K ve diğer bazı elementleri içeren kompoze gübreden, üretici firma önerileri doğrultusunda yaklaşık 20 g / asma olacak şekilde gübre kullanılmıştır. Kış budamasında asmanın gelişme kuvvetine göre 12-14 kıŞ gözü bırakılmıştır. Çeşitlerin dip gözlerinin verimlilik özelliğine göre Perle de Csaba'da kısa, Pembe Çekirdeksiz ve Superior Seedless çeşitlerinde ise karışık budama yapılmıştır. Yaz ortalarında sürgünlerin 1. ve 2. yaprakları kopartılmış ve külleme ilacı kullanılmıştır. Uygulama etkilerinin belirlenmesi amacıyla sürgün başına yaprak sayısı (her sürgünün yaprağı sayılarak sürgün sayısına bölerek), sürgün çapı (dijital kumpas ile her sürgünün 1. ve 2. yaprağının orta kısmındaki sürgün çapı), sürgün uzunluğu (metre ile), sürgün sayısı, yaprak alanı (OIV listelerinde belirtildiği gibi sürgünün 1/3'lük orta kısmından alınarak WinFolia bilgisayar programı ile belirlenmiştir), sürgün başına budama yaş ve kuru ağırlığı (hassas terazi ile), sürme oranı (kış budamasında bırakılan gözlerden çıkan primer sürgünler dikkate alınarak), asma başına salkım sayısı ve salkımlı asma oranı parametreleri dikkate alınmıştır.

Elde edilen rakamsal verilerin analizinde JMP ver. 5.1 (SAS Institute Inc., Cary, NC, USA) istatistik paket programı kullanılmış ve ortalamalar arasındaki gerçek önemli farklılıkları belirlemek için LSD testinden yararlanılmıştır.

\section{Bulgular}

Asmaların kış dinlenmesinde soğuk hava koşullarına maruz bırakılması şeklinde yapılan uygulama Perle de Csaba ve Superior Seedless üzüm çeşitlerinin sürme oranını önemli derecede etkilememiştir. Ancak, Pembe Çekirdeksiz çeşidinde kontrol asmalarında sürme oranı \%70.7 iken soğuklama uygulamasında \%85.3 oranında bir uyanma saptanmış ve uygulamanın etkisi önemli $(\mathrm{P}<0.05)$ bulunmuştur (Şekil 1). 
Nevşehir Bilim ve Teknoloji Dergisi TARGiD Özel Sayı 208-213 2016

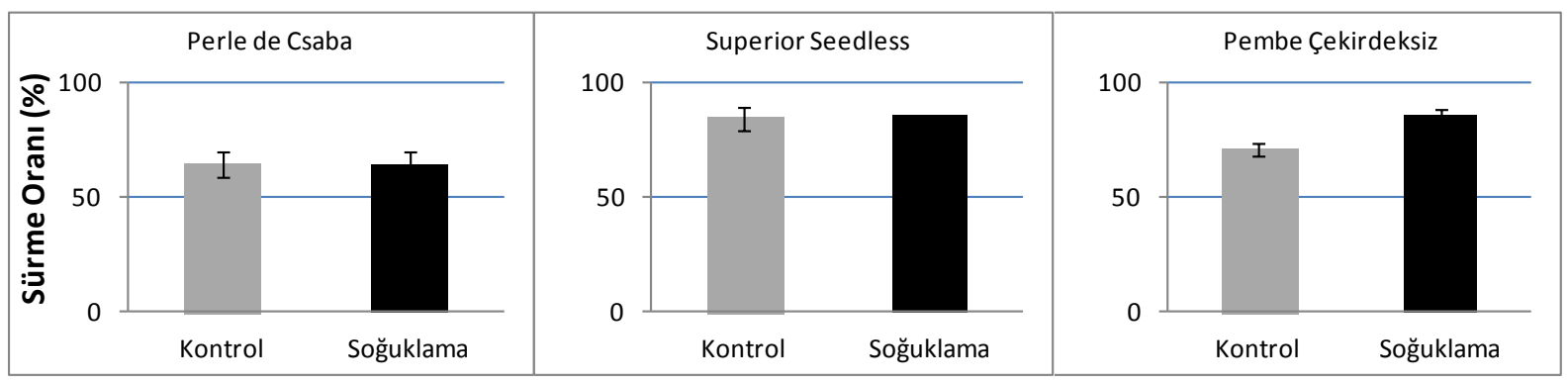

Şekil 1. Soğuklama uygulamasının üzüm çeşitlerinde sürme oranı (\%) üzerine etkileri (LSD \%5 Perle de Csaba: ö.d., Superior Seedless: ö.d., Pembe Çekirdeksiz: 4.90. ö.d.: önemli değil)

Üzüm çeşitlerinde soğuklamanın yaprak sayısı ve sürgün özellikleri üzerine etkileri Tablo 1'de sunulmuştur. Perle de Csaba çeşidinde soğuklama sürgün başına yaprak sayısını önemli derecede arttırrrken, sürgün özelliklerini önemli derecede etkilememiştir. Superior Seedless çeşidinde soğuklama istatistiki olarak önemli derecede daha kalın ve daha uzun sürgün oluşumunu teşvik etmiş, yaprak sayısı ve sürgün sayısı özelliklerini ise önemli derecede etkilememiştir. Diğer taraftan, soğuk uygulaması Pembe Çekirdeksiz çeşidinin yaprak sayısı ile sürgün gelişimi özelliklerini önemli derecede olumlu etkilemiştir. Bu çeşidin kontrol grubunda sürgün başına ortalama 19.5 yaprak oluşumu gerçekleşirken, soğuklama uygulamasında 21.1 olarak saptanmıştır. Benzer şekilde sürgün çapı 4.37 mm'den 5.18 mm’ye; sürgün uzunluğu 66.67 cm'den 75.17 cm'ye ve sürgün sayısı da 9.19'dan 10.87'ye yükselmiştir.

Tablo 1. Soğuklama uygulamasının üzüm çeşitlerinde yaprak sayısı, sürgün çapı, sürgün uzunluğu ve sürgün sayısı özelliklerine

\begin{tabular}{|c|c|c|c|c|c|}
\hline \multirow{2}{*}{$\begin{array}{l}\text { Perle de } \\
\text { Csaba }\end{array}$} & Soğuklama & $23.67 \pm 1.76 a$ & $3.49 \pm 0.30$ & $45.39 \pm 1.23$ & $7.72 \pm 0.70$ \\
\hline & LSD \% 5 & 3.22 & ö.d. & ö.d. & ö.d. \\
\hline \multirow{2}{*}{$\begin{array}{l}\text { Superior } \\
\text { Seedless }\end{array}$} & Soğuklama & $21.28 \pm 2.25$ & $4.05 \pm 0.04 \mathrm{a}$ & $56.13 \pm 2.86 a$ & $11.09 \pm 0.08 a$ \\
\hline & LSD \% 5 & ö.d. & 0.29 & 5.89 & ö.d. \\
\hline \multirow{2}{*}{$\begin{array}{l}\text { Pembe } \\
\text { Çekirdeksiz }\end{array}$} & Kontrol & $19.50 \pm 0.50 b$ & $4.37 \pm 0.38 b$ & $66.67 \pm 1.53 b$ & $9.19 \pm 0.20 b$ \\
\hline & Soğuklama & $21.10 \pm 0.17 \mathrm{a}$ & $5.18 \pm 0.08 a$ & $75.17 \pm 2.36 a$ & $10.87 \pm 0.34 a$ \\
\hline
\end{tabular}

ö.d.: önemli değil

Soğuklamanın yaprak alanı, budama artığı ağırlığı ve salkımlı asma oranına etkileri Tablo 2'de sunulmuştur. Perle de Csaba çeşidinde yaprak alanı ve budama yaş ağırlığı özellikleri uygulamalardan önemli derecede etkilenmemiş, budama kuru ağırlı̆̆ında ise bir miktar artı̧s sağlamıştır. Kuru ağırlıktaki artış, bu çeşidin verimlilik seviyesine yansıyarak salkımlı asma oranında önemli derecede artış görülmüştür. Kontrol grubu asmaların \%37.67'sinde salkım oluşumu belirlenirken, soğuklama uygulanan asmaların \%56.67'sinde salkım oluşumu saptanmıştır. Soğuklama, Superior Seedless ve Pembe Çekirdeksiz çeşitlerinin yaprak alanı ile budama yaş ve kuru ağırlığı özelliklerini önemli derecede olumlu etkilemiş̧ir. Özellikle yaprak alanı Superior Seedless'te soğuklama uygulamasıyla \%19.7 artışla 79.60 $\mathrm{cm}^{2 \prime}$ den $99.20 \mathrm{~cm}^{21}$ ye; Pembe Çekirdeksiz'de ise $\% 19.0$ artışla $88.35 \mathrm{~cm}^{21}$ den $109.12 \mathrm{~cm}^{21}$ ye yükselmiştir. Uygulama, Superior Seedless çeşidinin sürgün başına ortalama budama yaş ve kuru ağırlığını sırasıyla 
20.17 g'dan 24.10 g'a ve 10.64 g'dan 12.35 g'a yükseltmişstir. Benzer artışlar Pembe Çekirdeksiz çeşidinde de saptanmıştır. Asma başına salkım sayısı ve salkımlı asma oranı Perle de Csaba çeşidinde soğuklama uygulamasından önemli derecede olumlu etkilenirken, Pembe Çekirdeksiz çeşidinde bu özellikler bakımından farklılıklar önemli bulunmamıştır. Ancak, Pembe Çekirdeksiz çeşidinin ikinci yılda vermiş olduğu genel salkım sayısının az oluşu da dikkate alınmalıdır. Superior Seedless çeşidinde ise ikinci yaşında değerlendirmeye uygun sayılabilecek sayı ve nitelikte salkımlar oluşmadığından bu özellikler dikkate alınmamıştır.

Tablo 2. Soğuklama uygulamasının üzüm çeşitlerinde yaprak alanı, budama yaş ağırlığı, budama kuru ağırlığı ve salkımlı omca (\%) özelliklerine etkileri

\begin{tabular}{|c|c|c|c|c|c|c|}
\hline Çeşit & Uygulama & $\begin{array}{l}\text { Yaprak } \\
\text { Alanı }\end{array}$ & $\begin{array}{c}\text { Budama Yaş } \\
\text { Ağırlığı }\end{array}$ & $\begin{array}{c}\text { Budama Kuru } \\
\text { Ağırlığı }\end{array}$ & $\begin{array}{l}\text { Salkım } \\
\text { Sayısı }\end{array}$ & $\begin{array}{c}\text { Salkımlı Asma } \\
(\%)\end{array}$ \\
\hline \multirow{3}{*}{$\begin{array}{l}\text { Perle de } \\
\text { Csaba }\end{array}$} & Kontrol & $48.43 \pm 2.05$ & $9.20 \pm 0.33$ & $4.50 \pm 0.18 b$ & $3.70 \pm 0.22$ & $37.67 \pm 4.04 \mathrm{~b}$ \\
\hline & Soğuklama & $47.86 \pm 2.82$ & $9.14 \pm 0.04$ & $5.21 \pm 0.31 \mathrm{a}$ & $4.25 \pm 0.17$ & $56.67 \pm 5.77 \mathrm{a}$ \\
\hline & LSD \% 5 & ö.d. & ö.d. & 0.57 & 0.08 & 11.3 \\
\hline $\begin{array}{l}\text { Superior } \\
\text { Seedless }\end{array}$ & LSD \% 5 & 9.78 & 0.19 & 0.56 & & \\
\hline \multirow{2}{*}{$\begin{array}{l}\text { Pembe } \\
\text { Çekirdeksiz }\end{array}$} & Kontrol & $88.35 \pm 4.10 b$ & $22.18 \pm 0.92 b$ & $12.61 \pm 0.48 b$ & 1.2 & 33.3 \\
\hline & Soğuklama & $109.12 \pm 5.02 \mathrm{a}$ & $28.05 \pm 1.98 \mathrm{a}$ & $15.10 \pm 0.42 \mathrm{a}$ & 1.6 & 33.3 \\
\hline
\end{tabular}

ö.d.: önemli değil, *: yeterli veri alınamamıştır

\section{Tartışma ve Sonuç}

Asmalara soğuklama uygulaması Perle de Csaba çeşidinde yaprak sayısı, sürgün uzunluğu, asma başına salkım sayısı ve salkımlı asma oranını artırmıştır. Soğuk uygulaması, Superior Seedless çeşidinde sürgün çapı, sürgün uzunluğu, yaprak alanı, budama yaş ve kuru ağırlıklarını; Pembe Çekirdeksiz'de ise kış gözlerinde sürme oranı, yaprak sayısı, sürgün çapı, sürgün uzunluğu, yaprak alanı, budama yaş ve kuru ağırlıkları özelliklerini olumlu etkilemiştir.

Ülkemiz koşullarında ticari değeri henüz önemli seviyelerde bulunmayan, ancak en erken olgunlaşanlar arasında yer alan Perle de Csaba [5, 6] için soğuklama uygulaması yaprak sayısı, budama kuru ağırlı̆̆ı, salkım sayısı ve salkımlı asma oranı dışındaki özellikleri önemli derecede etkilememiştir. Yani soğuklamanın bu çeşidin vejetatif gelişmesini diğer çeşitlere göre daha az etkilediği, ancak verimlilik seviyesini belirgin bir şekilde etkilediği söylenebilir. Diğer taraftan Superior Seedless ve Pembe Çekirdeksiz çeşitlerinin vejetatif gelişmeleri soğuk uygulamasından önemli oranda pozitif etkilenmiştir. Asmalarda çeşide özgü soğuklama ihtiyacının belirlenmesine yönelik ulaşılabilir nitelikte fazla literatür bilgisi olmamakla birlikte [2], bu çalışmadan elde edilen bulgular kış dinlenmesi döneminde asmaların bir süre soğuk havaya tabii tutulmasının genel gelişme özelliklerine olumlu etkide bulunduğunu ve bu bakımdan, Vasquez [3]'in de belirttiği gibi çeşitler arasında büyük farklılıklar olduğunu işaret etmektedir. Özellikle örtü altında erkenci üzüm yetiştiriciliğinde, çeşitlerin bu tür tepkilerinin bilinmesi ve buna göre uygulama yapılması büyük önem arz etmektedir [7]. Zira kış döneminde soğuklama uygulaması Akdeniz Bölgesinde örtü altı bağcılığ 1 yapmak isteyen bazı üreticilerin karşılaştığı önemli sorunlardan birisi olduğu düşünülmektedir. Son y1llarda geliştirilen kaliteli yeni 
erkenci çeşitlerin soğuk uygulamalarına tepkileri üzerine yürütülecek çalışmalar, özellikle örtü altı bağcılı̆̆ 1 bakımından faydalı olacaktır.

\section{Kaynaklar}

[1] Weinberger J. H., "Chilling requirements of peach varieties" Proceedings of American Society for Horticultural Science, 56, 122-128, 1950.

[2] Botelho R. V., Pavanello A. P., Pires E. J. P., Terra M. M., Müller M. M. L., "Effects of chilling and garlic extract on bud dormancy release in Cabernet Sauvignon grapevine cuttings" American Journal of Enology and Viticulture, 58, 402-404, 2007.

[3] Vasquez S. J., "Winter Chilling Requirements for Grapes" San Joaquin Valley Grape Symposium January 7, C.P.D.E.S. Hall 172 W. Jefferson Avenue Easton, California, 2009.

[4] Uzun H .İ., “Bağcılık” el kitabı, Akdeniz Üniversitesi Ziraat Fakültesi, Antalya, 2003.

[5] Sabır A., "Bazı Üzüm Çeşit ve Anaçlarının Ampelografik ve Moleküler Karakterizasyonu" Çukurova Üniversitesi Fen Bilimleri Enstitüsü Doktora Tezi, 154s, 2008.

[6] Ergenoğlu F., "Çukurova koşullarında yetişen yabancı kökenli erkenci üzüm çeşitlerinin adaptasyonu üzerinde bir araştırma" DOĞG, Türk Tarım ve Ormancılık Dergisi, 12, 11-18, 1988.

[7] Sabır A., " Örtüaltı bağcılığı ve Türkiye için önemi" Agromedya, 1 (3), 74-77, 2013. 